\title{
A STUDY OF LIPID PROFILE AND ASSESSMENT OF CARDIOVASCULAR RISK IN SUBCLINICAL HYPOTHYROIDISM
}

\author{
Kishore Chander Prem Kumar ${ }^{1}$, Prakash Subramanian²
}

1 Postgraduate Student, Department of General Medicine, Government Stanley Medical College and Hospital, Chennai, Tamilnadu, India.

${ }^{2}$ Assistant Professor, Department of General Medicine, Government Stanley Medical College and Hospital, Chennai, Tamilnadu, India.

\begin{tabular}{l}
\hline ABSTRACT \\
BACKGROUND \\
Studies on association between subclinical hypothyroidism and lipid profile have produced conflicting results. The assessment of \\
cardiovascular risk in subclinical hypothyroid patients is rare in Indian scenario. We wanted to study the lipid profile in subclinical \\
hypothyroid patients and assess the cardiovascular risk in subclinical hypothyroid patients by using atherogenic indexes.
\end{tabular}

\section{METHODS}

In this study, newly diagnosed untreated subclinical hypothyroid patients were studied for dyslipidaemia and cardiovascular risk is assessed using lipid ratios- Atherogenic Index of Plasma and Castelli Risk Index. To find the significant difference between the bivariate samples in independent groups, unpaired sample t-test was used and to find the significance in categorical data, ChiSquare test and Fisher's Exact test were used. In all the above statistical tools, the probability value 0.05 was considered as significant.

\section{RESULTS}

Total cholesterol, triglyceride and VLDL-C levels shows statistically significant association among subclinical hypothyroid patients compared to euthyroid subjects. Castelli Risk Index-II showed statistically significant association in subclinical hypothyroid patients compared to euthyroid controls.

\section{CONCLUSIONS}

The positive association of subclinical hypothyroid patients and dyslipidaemia warrants that all patients with subclinical hypothyroidism should be evaluated for deranged lipid profile parameters. Castelli Risk Index-II calculated as LDL-C/HDL-C could be used as a better predictor of cardiovascular risk compared to the other risk assessment ratios Atherogenic Index of Plasma and Castelli Risk Index I.

HOW TO CITE THIS ARTICLE: Kumar KCP, Subramanian P. A study of lipid profile and assessment of cardiovascular risk in subclinical hypothyroidism. J. Evolution Med. Dent. Sci. 2019;8(16):1318-1320, DOI: 10.14260/jemds/2019/293

\section{BACKGROUND}

Subclinical hypothyroidism is defined as a biochemical evidence of thyroid hormone deficiency with few or no apparent clinical features of hypothyroidism. Subclinical hypothyroidism is characterized by normal serum free thyroxine (fT4) and normal serum free triiodothyronine (fT3) and elevated levels of serum thyroid stimulating hormone (TSH).[1]

Subclinical hypothyroidism is a common disorder with a prevalence of $2.8-4.4 \%$ in males and $7.5-8.5 \%$ in females world-wide.[2]

Overt hypothyroidism has been associated with abnormal lipid profile parameters such as elevated levels of total cholesterol (TC), low density lipoproteins (LDL-C), triglycerides (TG) and reduced levels of high-density lipoproteins (HDL-C) as established by various studies. Such deranged lipid profile parameters are well associated with cardiovascular disease morbidity and mortality.[3]

'Financial or Other Competing Interest': None.

Submission 04-01-2019, Peer Review 05-04-2019,

Acceptance 14-04-2019, Published 22-04-2019.

Corresponding Author:

Dr. Prakash Subramanian,

14/20, P. C. Hostel Road,

Chetpet, Chennai-600031,

Tamilnadu, India.

E-mail: pvastanlee@gmail.com

DOI: $10.14260 /$ jemds $/ 2019 / 293$
Studies conducted to establish the relationship between subclinical hypothyroidism and abnormalities in lipid profile have produced conflicting results.[4] Some studies have established a significant relationship between subclinical hypothyroidism and metabolic syndrome thereby increased risk of cardiovascular diseases.

Apart from individual lipid parameters that has been measured in conventional lipid profile, serum lipid profile ratios such as LDL-C/HDL-C, TC/HCL-C, TG/HDL-C have been widely used and is shown to be a better predictor of cardiovascular risk than individual lipid parameters.[5] Small dense lipoproteins (sdLDL-C), a subtype of LDL-C is well known for its atherogenic potential. The Atherogenic Index of Plasma (AIP) is calculated as log [TG/HDL-C] and is a surrogate marker of sdLDL-C there having a superior prediction advantage for cardiovascular risk assessment than the previously used lipid parameters. ${ }^{[5,6]}$

Thyroid hormone has inotropic and chronotropic effects on the heart. Reduced blood volume and increased peripheral vascular resistance causes prolonged circulation and reduced blood flow to tissues. ${ }^{(7)}$

Both Subclinical and overt hypothyroid patients aged 65 $\&$ above showed correlation with cardiovascular outcome in a prospective study.(8)

Some studies suggest a benefit in cardiovascular outcome following treatment primarily in middle age. $(9,10)$

The effects of overt hypothyroidism on lipid parameters has been extensively studied. However, the studies relating the association between the subclinical hypothyroidism and 
the lipid parameters are few. In the Indian clinical scenario such studies are lacking. Subclinical hypothyroidism having been diagnosed with greater frequency in recent times particularly among the women population it has become necessary to study extensively the relation between $\mathrm{SH}$ and cardiovascular risk related to deranged lipid profile.

\section{Aims \& Objectives}

To study the lipid profile in subclinical hypothyroid patients and to assess the cardiovascular risk in subclinical hypothyroid patients by using atherogenic indexes.

\section{METHODS}

\section{Type of Study}

Comparative Cross-Sectional Study.

\section{Cases}

Patients with few or no clinical manifestation of hypothyroidism, but elevated Serum-TSH Levels.

\section{Controls}

Patients with normal Serum-TSH Levels.

Patients of both sexes attending the Outpatient Department of Endocrinology, Government Stanley Medical College Hospital, Chennai, having one or more clinical manifestations of hypothyroidism, e.g., fatigue, weakness, loss of strength, loss of stamina, weight gain, coarse dry hair, dry, rough and pale skin, hair loss, cold intolerance, muscle cramps, frequent muscle aches, constipation, depression, irritability, memory loss, and in women abnormal menstrual cycle were recruited for the study, for a duration of Six Months.
These patients were screened for fT3, fT4, and TSH. 50 patients with raised TSH(TSH $>5 \mathrm{mIU} / \mathrm{L}$ ) with normal fT3, fT4 were included in the study and evaluated further for lipid profile pertaining to TC, TGs, High density lipoprotein cholesterol (HDL), and Low-density lipoprotein-cholesterol (LDL-C). 50 patients with normal TSH were kept as control. Based on the lipid profile values the following atherogenic indices were calculated-

1. Atherogenic Index of Plasma-Log[TG/HDL

2. Castelli Risk Index -I - TC/HDL-C

3. Castelli Risk Index-II - LDL-C/HDL-C

The sample size was taken based on the convenience of the study.

\section{Inclusion Criteria}

Newly diagnosed and untreated cases of subclinical hypothyroidism

\section{Exclusion Criteria}

Known hypothyroidism cases, thyroidectomy cases, patient with history of external radiation, previous radioactive iodine therapy.

Patient on statins, oral contraceptive pills and drugs that affect thyroid status [Alpha blockers, glucocorticoids, dopamine analogues-reduces TSH] and lipid profile.

Patients with Diabetes mellitus, renal failure, Hepatic failure. Pregnant women.

\section{Statistical Methods}

The data was collected and analysed using standard statistical chi-square test, $\mathrm{P}<0.05$ statistically significant. Data was entered in Microsoft excel and analysis was done using SPSS version 22.

\section{RESULTS}

\begin{tabular}{|c|c|c|c|c|}
\hline Parameters & Values & Cases & Controls & 'p' Value \\
\hline Total Cholesterol & $\begin{array}{l}<240 \mathrm{mg} \% \\
>240 \mathrm{mg} \%\end{array}$ & $\begin{array}{l}44(88 \%) \\
6(12 \%)\end{array}$ & $\begin{array}{c}50(100 \%) \\
0\end{array}$ & 0.040 \\
\hline Triglycerides & $\begin{array}{l}<200 \mathrm{mg} \% \\
>200 \mathrm{mg} \%\end{array}$ & $\begin{array}{l}41(82 \%) \\
9(18 \%) \\
\end{array}$ & $\begin{array}{c}48(96 \%) \\
2(4 \%)\end{array}$ & 0.075 \\
\hline HDL-Cholesterol & $\begin{array}{l}<40 \mathrm{mg} \% \\
>40 \mathrm{mg} \%\end{array}$ & $\begin{array}{l}12(24 \%) \\
38(76 \%)\end{array}$ & $\begin{array}{l}8(16 \%) \\
42(84 \%)\end{array}$ & 0.384 \\
\hline LDL-Cholesterol & $\begin{array}{l}<130 \mathrm{mg} \% \\
>130 \mathrm{mg} \%\end{array}$ & $\begin{array}{l}39(78 \%) \\
11(22 \%) \\
\end{array}$ & $\begin{array}{c}48(96 \%) \\
2(4 \%)\end{array}$ & 0.078 \\
\hline VLDL-Cholesterol & $\begin{array}{l}<30 \mathrm{mg} \% \\
>30 \mathrm{mg} \%\end{array}$ & $\begin{array}{l}32(64 \%) \\
18(36 \%)\end{array}$ & $\begin{array}{c}50(100 \%) \\
0\end{array}$ & 0.000 \\
\hline $\begin{array}{l}\text { Atherogenic Index of Plasma } \\
\text { (Log [TG/HDL-C]) }\end{array}$ & $\begin{array}{l}0.11-0.21 \\
>0.21\end{array}$ & $\begin{array}{c}5(10 \%) \\
45(90 \%)\end{array}$ & $\begin{array}{c}4(8 \%) \\
46(92 \%)\end{array}$ & 1.000 \\
\hline $\begin{array}{l}\text { Castelli Risk Index-I } \\
\text { (TC/HDL-C) }\end{array}$ & $\begin{array}{l}<5 \\
>5\end{array}$ & $\begin{array}{l}41(82 \%) \\
9(18 \%)\end{array}$ & $\begin{array}{c}47(94 \%) \\
3(6 \%)\end{array}$ & 0.163 \\
\hline $\begin{array}{l}\text { Castelli Risk Index-II } \\
\text { (LDL-C/HDL-C) }\end{array}$ & $\begin{array}{l}<3 \\
>3\end{array}$ & $\begin{array}{l}38(76 \%) \\
12(24 \%) \\
\end{array}$ & $\begin{array}{c}49(98 \%) \\
1(2 \%)\end{array}$ & 0.002 \\
\hline
\end{tabular}

Table 1. Analysis of Study Parameters in Cases \& Controls

There is a statistically significant association among cases with elevated total cholesterol, triglycerides, VLDL-C and Castelli Risk Index-II than Controls.

There is no statistically significant association with HDL-C, LDL-C, Atherogenic Index of Plasma and Castelli Risk Index-I among cases and controls.

\section{DISCUSSION}

In our study the mean age of cases was $34.88+/-14.081$ and the mean age for control subjects were $32.50+/-9.368$. Out of 50 subjects in the case group, $24 \%$ were in the age group of
13 to 20 years, $42 \%$ were in the age group of 21 to 40 years, $30 \%$ of subjects belongs to the age group between 41 to 60 years and $4 \%$ were $>60$ years of age. In the case group $98 \%$ (49 patients) of subjects were female and $2 \%$ were male. 
Subclinical hypothyroid patients with TSH values more than $10 \mathrm{mIU} / \mathrm{L}$ are invariably treated with thyroxine replacement. Our study taking into consideration the subclinical hypothyroid subjects with TSH values less than 10 $\mathrm{mIU} / \mathrm{L}$ and analysing the lipid profile and cardiovascular risk index ratios, we intended to formulate a guide for thyroxine replacement in such patients with regard to benefit from cardiovascular morbidity and mortality.

In the lipid profile parameters, $12 \%$ of case subjects had total cholesterol levels of $>/=240 \mathrm{mgs} / \mathrm{dl}$ which is in the high-risk range group for developing cardiovascular morbidity and mortality. In the control group no subjects had total cholesterol values in the high-risk group. There is a statistically significant association among cases with elevated total cholesterol compared to controls.

$58 \%$ of subjects in the case group had triglyceride levels of $<150 \mathrm{mgs} / \mathrm{dl}$ which falls in the desirable range. $24 \%$ of cases had triglyceride values between 150-199 mgs/dl and $18 \%$ of patients had values between $200-499 \mathrm{mgs} / \mathrm{dl}$ which falls into normal risk and high risk for cardiovascular morbidity/ mortality respectively. Among the controls 11\% of subjects had triglyceride levels in the high-risk range. There is a statistically significant association among the cases with triglyceride levels compared to the controls.

In the case group $24 \%$ of subjects had HDL-C values $<40$ mgs/dl which falls in the high risk for developing cardiovascular disease. In the control group $16 \%$ of subjects had HDL-C levels in the high-risk group. There is no statistically significant association with HDL-C among cases and controls.

In the case group $4 \%$ had LDL-C levels in the high-risk range and only $2 \%$ had levels in the very high-risk range. In the control group $2 \%$ and $1 \%$ of subjects had LDL-C levels in the high risk and very high-risk range respectively. There is no statistically significant association among cases and controls with LDL-C levels.

$36 \%$ of cases had VLDL-C levels $>30 \mathrm{mgs} / \mathrm{dl}$ which is in the high-risk range for developing cardiovascular events. $18 \%$ of subjects among the control group falls in the high-risk range. There is a statistically significant association among cases with VLDL-C than controls.

The Atherogenic Index of Plasma is calculated as Log [TG/HDL-C]. $90 \%$ of cases and $92 \%$ of controls had values $>$ 0.21 which is in the high-risk range. There is no statistically significant association among cases and controls with Log [TG/HDL-C] values.

Castelli Risk Index-I is calculated as ratio of TC/ HDL-C. $18 \%$ of subjects in the control group had ratio of $>5$ which is in the high-risk range, while $12 \%$ subjects of the control group had ratios in the high-risk group. $46 \%$ and $36 \%$ of the case group subjects had ratios in the borderline risk and low risk respectively for developing cardiovascular event. There is no statistically significant association among cases and controls with Castelli Risk Index-I [TC/HDL-C].

Castelli Risk Index- II is calculated as ratio of LDL-C/ HDL-C.

\section{CONCLUSIONS}

Subclinical hypothyroid patients have significantly deranged lipid parameters including statistically significant elevated total cholesterol, triglycerides and VLDL-C compared to euthyroid individuals. Among the lipid ratios the Castelli Risk Index II calculated as LDL-C/HDL-C shows statistically significant association and could be used as a better predictor of cardiovascular risk compared to the other risk ratios Atherogenic Index of Plasma and Castelli Risk Index-I.

\section{REFERENCES}

[1] Jameson LJ. Harrison's Endocrinology. $4^{\text {th }}$ edn. McGraw-Hill Education 2016: p. 86.

[2] Canaris GJ, Manowitz NR, Mayor G, et al. The Colorado thyroid disease prevalence study. Arch Intern Med 2000;160(4):526-34.

[3] Pucci E, Chiovato L, Pinchera A. Thyroid and lipid metabolism. Int J Obes Relat Metab Disord 2000;24(Suppl 2):S109-S12.

[4] Efstathiadou Z, Bitsis S, Milionis HJ, et al. Lipid profile in subclinical hypothyroidism: Is L-thyroxine substitution beneficial? Eur J Endocrinol 2001;145(6):705-10.

[5] Baliarsingh S, Sharma N, Mukherjee R. Serum uric acid: marker for atherosclerosis as it is positively associated with "atherogenicinex of plasma". Arch Physiol Biochem 2013;119(1):27-31.

[6] Dobiasova M. AIP-Atherogenic Index of Plasma as a significant predictor of cardiovascular risk: from research to practice. Vnitr Lek 2006;52(1):64-71.

[7] Kahaly GJ, Dillmann WH. Thyroid hormone action in the heart. Endocr Rev 2005;26(5):704-28.

[8] Cappola AR, Fried LP, Arnold AM, et al. Thyroid status, cardiovascular risk and mortality in older adults. JAMA 2006;295(9):1033-41.

[9] Kvetny J, Heldgaard PE, Bladbjerg EM, et al. Subclinical hypothyroidism is associated with a low-grade inflammation, increased triglyceride levels and predicts cardiovascular disease in males below 50 years. Clin Endocrinol (Oxf) 2004;61(2):232-8.

[10] Biondi B, Cooper DS. The clinical significance of subclinical thyroid dysfunction. Endocr Rev 2008;29(1):76-131. 